\title{
Ocean Forests: Breakthrough Yields for Macroalgae
}

Mark E. Capron, PE

OceanForesters

Ventura, CA, USA

MarkCapron@oceanforesters.org

Reginald Blaylock, PhD

Thad Cochran Marine Aquaculture Center, School of Ocean Science and Engineering

University of Southern Mississippi

Ocean Springs, MS, USA

Reg.Blaylock@usm.edu

Kelly Lucas, $\mathrm{PhD}$

Thad Cochran Marine Aquaculture Center, School of Ocean Science and Engineering

University of Southern Mississippi

Ocean Springs, MS, USA

Kelly.Lucas@usm.edu

Michael D. Chambers

School of Marine Science and Ocean Engineering

University of New Hampshire

Durham, NH, USA

Michael.Chambers@unh.edu

Jim R. Stewart, PhD

OceanForesters

Ventura, CA, USA

JimStewart@oceanforesters.org

Steven F. DiMarco, PhD

Department of Oceanography

Texas A\&M University

College Station, TX, USA

SDimarco@email.tamu.edu

Kerri Whilden, $\mathrm{PhD}$

Department of Oceanography

Texas A\&M University

College Station, TX, USA

KWhilden@tamu.edu

Binbin Wang, $\mathrm{PhD}$

Department of Oceanography

Texas A\&M University

College Station, TX, USA

BWang314@tamu.edu

MH Kim, PhD

Texas A\&M University

College Station, TX, USA

M-Kim3@tamu.edu
Zach Moscicki

School of Marine Science and Ocean Engineering

University of New Hampshire

Durham, NH, USA

MoscickiZ@gmail.com

Corey Sullivan

School of Marine Science and Ocean Engineering

University of New Hampshire

Durham, NH, USA

Corey.Sullivan@unh.edu

Igor Tsukrov

School of Marine Science and Ocean Engineering

University of New Hampshire

Durham, NH, USA

Igor.Tsukrov@unh.edu

M. Robinson Swift

School of Marine Science and Ocean Engineering

University of New Hampshire

Durham, NH, USA

MRSwift@unh.edu

Scott C. James, PhD, PE

Departments of Geosciences and

Mechanical Engineering

Baylor University, Waco, TX, USA

SC_James@baylor.edu

Maureen Brooks

Horn Point Laboratory

University of Maryland Center for Environmental Science Cambridge, MD, USA

MBrooks@umces.edu

Stephan Howden, $\mathrm{PhD}$

School of Ocean Science and Engineering

University of Southern Mississippi

Ocean Springs, MS, USA

Stephan.Howden@usm.edu

Suzanne Fredericq

Department of Biology

University of Louisiana at Lafayette

Lafayette, LA, USA

slf9209@louisiana.edu

Stacy A. Krueger-Hadfield

Department of Biology

Univ. of Alabama Birmingham

Birmingham, AL, USA

sakh@uab.edu 
Antoine De Ramon N'Yeurt

Pacific Centre for Environment and Sustainable Development

The University of the South Pacific

Suva, Fiji

nyeurt_a@usp.ac.fj

Chris Webb

AI Control Technologies
Boca Raton, FL, USA

chris.webb@ai-ctec.com

Don Piper

OceanForesters

Ventura, CA, USA

dpiper1111@gmail.com
Abstract: The US Department of Energy Advanced Research Projects Agency - Energy (ARPA-E) MacroAlgae Research Inspiring Novel Energy Research (MARINER) program is encouraging technologies for the sustainable harvest of large funding research of macroalgae for biofuels at less than $\mathbf{\$ 8 0}$ per dry metric ton (DMT). The Ocean Forests team, led by the University of Southern Mississippi, is developing a complete managed ecosystem where nutrients are transformed and recycled. The team's designs address major bottlenecks in profitability of offshore aquaculture systems including economical moored structures that can withstand storms, efficient planting, managing and harvesting systems, and sustainable nutrient supply. The work is inspired by Lapointe [1] who reported yields of Gracilaria tikvahiae equivalent to 127 DMT per hectare per year (compared with standard aquaculture systems in the range of 20 to $40 \mathrm{DMT} / \mathrm{ha} / \mathrm{yr}$ ). This approach offers the potential for breakthrough yields for many macroalgae species. Moreover, mini-ecosystems in offshore waters create communities of macroalgae, shellfish, and penned finfish, supplemented by visiting free-range fish that can increase productivity, produce quality products, and create jobs and income for aquafarmers. Additional benefits include reduced disease in fish pens, cleaning contaminated coastal waters, and maximizing nutrient recycling. Cost projections for a successful, intensive, scaled system are competitive with current prices for fossil fuels.

Keywords: Gracilaria; Gracilaria tikvahiae; biofuels; macroalgae; seaweed; aquaculture; breakthrough yields; algae; ocean afforestation; seafood

\section{INTRODUCTION}

Ocean Forestry is an extension of natural processes in marine ecosystems where macroalgae, bacteria, and animals transform and recycle nutrients. Ocean Forestry supplements natural processes by incorporating finfish/shellfish (both farmed and free-range) and multiple species of macroalgae to increase biomass production while providing a path to market. A simplified nutrient transformation cycle (excluding microscopic species such as plankton and bacteria) is shown in Fig. 1.

The task outlined by the US Department of Energy Advanced Research Projects Agency - Energy (ARPA-E) is [2]:

Funded by ARPA-E Funding Opportunity No. DE-FOA- 0001726 MARINER contract DE-AR0000916-1, University of Southern Mississippi, prime contractor.

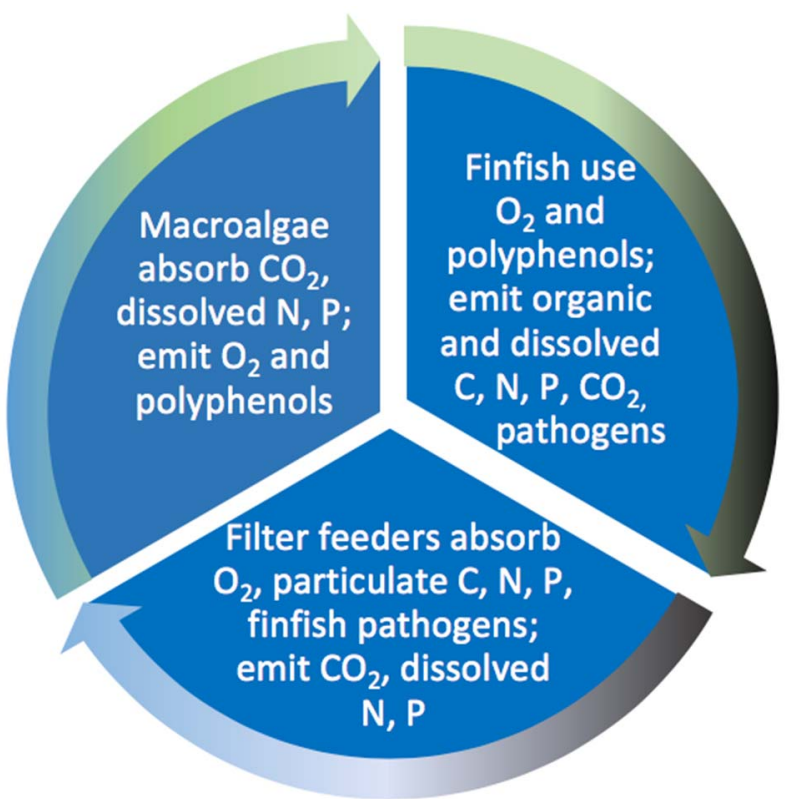

Fig. 1. Simplified ocean forest nutrient recycling

[T] o significantly broaden the opportunities for macroalgae to be a significant energy contributor to a future low-carbon world, especially for the production of biofuels.... [Through] the development of transformational technologies to enable a U.S. based macroalgae industry capable of producing up to 2 Quads of bioenergy by 2050, while also supplying the world's ever-expanding need for animal feed. The ARPA-E MARINER Program will meet these goals by developing innovative cultivation $\&$ harvest systems able to produce macroalgae biomass that is cost competitive with terrestrial biomass at energy-relevant scale. The primary technical target is to demonstrate [at scale] Biomass Production Cost $\leq \$ 80 /$ dry metric ton, without direct application of synthetic fertilizer.

Our analysis shows that higher productivity (thus lower cost per ton) results from natural nutrient recycling in a complete ecosystem, which also provides both ecological and economic benefits. For example, Buck et al. [3] found that about four wet 
tons of shellfish ${ }^{1}$ and/or seaweed will remove the organic nitrogen emitted by 1 ton of finfish. More shellfish or seaweed (quantities adjusted to the level of excess nutrients) could revive dead zones. In addition, macroalgae could expand local fish populations through the food and habitat it provides. Economic benefits include the removal of both sea lice [4] and fish feces by shellfish growing around fish pens, which potentially reduces the cost of finfish aquaculture and decreases coastal contamination from fish farms.

Results of this one-year project include a technoeconomic analysis (TEA) of how an ocean forest ecosystem could eventually achieve the ARPA-E goal of production costs $<\$ 80 /$ dry metric ton (DMT) of biomass plus a proposal for a Phase 2 small demonstration to de-risk key elements.

\section{OVERVIEW OF THE APPROACH}

Our team will design and demonstrate complete systems for use with any type of macroalgae so that anyone could adapt the technology for their species and local conditions. Several team members have worked with the University of New Hampshire Open Ocean Aquaculture research farm, which tested technologies for the culture of native, cold-water finfish and shellfish species in exposed oceanic environments. The study site was located $12 \mathrm{~km}$ off the New Hampshire coast in 52-m deep water [6]. The system demonstrated the nutrientconversion cycle in Fig. 1. A similar UNH site close to shore now raises fish, shellfish, and macroalgae biomass, all of which are harvested and sold to local markets.

This Ocean Forest project plans to grow native macroalgae in the Gulf of Mexico (GoM). Biologists recommended the red seaweed Gracilaria tikvahiae [7], which grows to a length of about $30 \mathrm{~cm}$ and yields about $12 \mathrm{DMT} / \mathrm{ha} / \mathrm{yr}$ of biomass when cultivated in ponds [8]. However, ARPA-E assumes that a minimum of $25 \mathrm{DMT} / \mathrm{ha} / \mathrm{yr}$ is needed to meet the $\$ 80 / \mathrm{DMT}$ target [2].

\section{DESIGN COMPONENTS}

\section{A. Spiderweb Structure}

The major issue in the GoM is damage from hurricanes and storms. All structures permitted in U.S. waters of the GoM must have a hurricane-contingency plan. We plan to submerge the farm at a protective depth of at least $40 \mathrm{~m}$, but at least $10 \mathrm{~m}$ above the seafloor to avoid dragging the macroalgae and shellfish in the mud. In minor storms, the system sinks a few meters to lessen the effects of large waves on the macroalgae and structure to reduce loss of crop and structural damage.

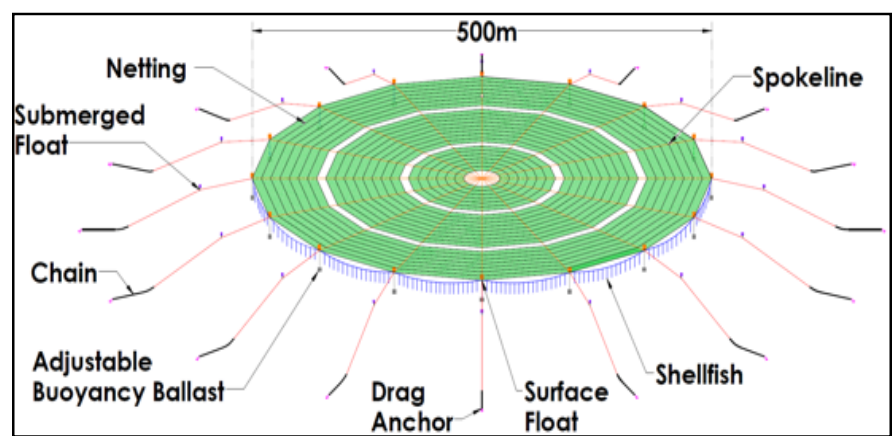

Fig. 2. Spiderweb structure overview.

Fig. 2 shows a macroscale view of a single unit, which at full scale has a $0.5-\mathrm{km}$ diameter. Netting or rope substrate for algae growth is tensioned between structural radial spokelines. Remote-controlled, adjustable-buoyancy float-ballast systems are located at the connections of the spokelines and anchorlines. Shellfish baskets are suspended from the lines between floats. Openings in the growing area could allow marine mammals to surface when passing under the structure. We are collaborating with NOAA and other specialists to ensure that the final design minimizes negative interactions with marine animals.

The structure was inspired by the structural resilience of a spider web. Relying only on compliant rope structures, distributed buoyancy, and changeable position in the water column, the system can survive the extreme conditions in the GoM. The spoked circular design distributes resistance to hydrodynamic loads regardless of current direction. The spoked structural foundation also allows for deployed geometries that can easily handle the inaccuracies of marine anchor deployments.

The structure also could be used for sugar kelp and other species using longlines instead of the netting substrate shown.

The spider-web design ${ }^{2}$ shown in Fig. 2 has no surface floats over the main seaweed grow-ropes (only around the periphery) allowing the Mow-Harvest-Bag System to move unimpeded in a continuous spiral over the seaweed.

Together with the fish species attracted by the structure, the shellfish metabolize nutrients in planktonic microorganisms into forms more readily available to macroalgae. Increased nutrient levels in the macroalgae "forest" increase biomass yields. This ecosystems approach to nutrient supply means species valuable to the seafood market can be co-produced to help offset the cost of the structure.

As macroalgae age, they release carbon and nutrients they have absorbed. The larger their size the more leaf tip break-off and mucilage emissions. Therefore, frequent mowing to maintain macroalgae biomass density between 1 and $10 \mathrm{DMT} /$ ha could assist breakthrough yields of any macroalgae.

\footnotetext{
2 Developed by OceanForesters and University of New Hampshire
} structural engineers.

\footnotetext{
Recent unpublished work by M.D. Chambers, et al. has reduced this to $3: 1$ per ton of finfish.
} 


\section{B. Depth Control System}

The depth-control system ${ }^{3}$ is designed for unsheltered water subject to storms. Fig. 3 illustrates two depth positions; the top one shows macroalgae at their optimum growing depth and the lower one depicts the suspended ballasts resting on the seafloor when the structure is submerged, but the macroalgae and shellfish and penned fish are several meters above the seafloor.
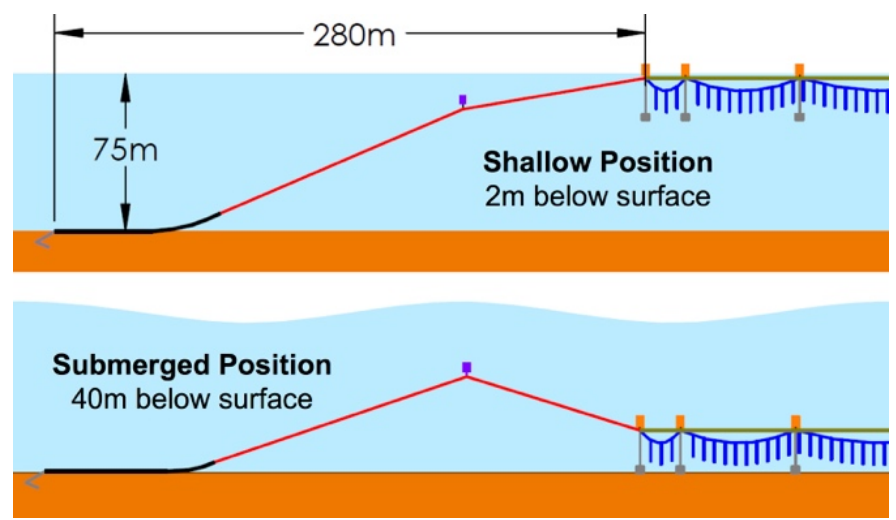

Fig. 3. System schematics showing surface and submerged positions

These float-ballast systems at the end of each spokeline change the operating depth using minimal energy. The operating depth in the surfaced position is passively controlled by surface floats while the depth in the submerged position is passively controlled by ballast weights hanging about $15 \mathrm{~m}$ below the surface floats. When activated, valves on the ballast flood the interior tank, which sinks the system. When surface conditions improve, compressed air from the float forces water out of the ballast chamber and the system rises. Intermediate mooring-line floats maintain tension in the mooring legs regardless of position in the water column.

When conditions are relatively calm, the system operates at a growing depth of about $2 \mathrm{~m}$, sufficiently deep to avoid surface chop, but allowing for optimal light absorption for the species involved. When storm conditions are rough, the system is submerged below the highest energy wave environment allowing the system to minimize exposure to extreme events. Data from Hurricane Andrew [9] indicated that submerging the system to $50 \mathrm{~m}$ cut the hydrodynamic loads on the system by more than $50 \%$. This means that a cost-effective system need only be sized for the moderate conditions at depth.

\section{Perennial Macroalgae Growth-Breakthrough Yields}

"Typical" macroalgae yields are $\sim 30 \mathrm{DMT} / \mathrm{ha} / \mathrm{yr}$, but Lapointe in a year-long experiment showed that Gracilaria tikvahiae could produce $127 \mathrm{DMT} /$ ha/year [1], provided the macroalgae is maintained at a low density by frequent harvests. Lapointe harvested Gracilaria weekly and maintained a density of 2 to $8 \mathrm{DMT} /$ ha while providing optimal nitrate and phosphate, which we can supply using nutrients from waste products recovered from the energy-conversion process.

Increased conversion of organic to inorganic nutrients increases macroalgae yields and reduces nutrient shadows. As they approach maximum size/density, macroalgae (more so kelp than Gracilaria) lose mass due to tip breakoff and mucilage emissions [10]. Animal biomass facilitates conversion of organic nutrients to inorganic nutrients. These "losses" of infarm organic nutrients are recovered by shellfish and finfish, whose excretions nourish the macroalgae.

Recent information [11] demonstrates that some plant and animal ecosystems are shrinking in response to global warming. High seawater temperatures also could reduce growth of other organisms. Our systems could counteract this by submerging the seaweed to cool the plants in deeper waters.

\section{Plant-Mow-Harvest-Bag System}

Gracilaria tikvahiae, which grows to $30 \mathrm{~cm}$, will be cultivated at an optimum depth of about $2 \mathrm{~m}$. The seeding process features a double-layered net system as shown in Fig. 4. Automated equipment contains a supply of macroalgae cuttings that are distributed over the bottom substrate net. Then a top net is rolled over the cuttings and sealed to the bottom net with staples. The mesh openings of the top netting allow the Gracilaria to grow freely and expand between and through the netting layers. The top netting ensures that macroalgae will remain in place when submerging the growth system.

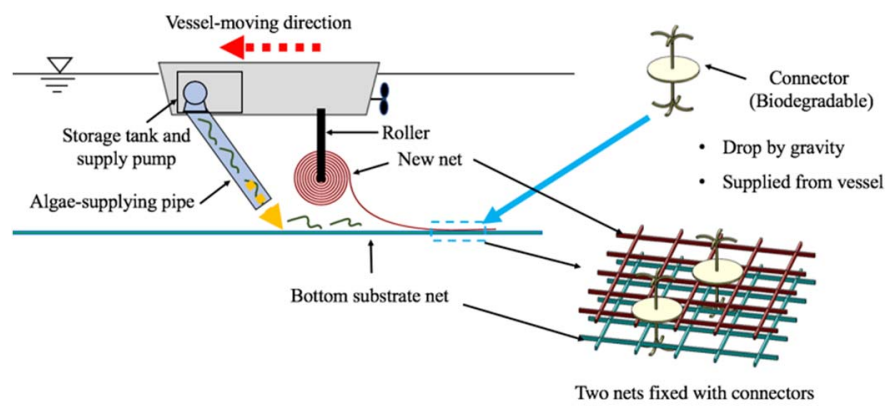

Fig. 4. Automated seeding of Gracilaria tikvahiae between two nets.

When it reaches about $10 \mathrm{~cm}$ high, the Gracilaria is mowed by a special cutter pushed by a wheeled autonomous vehicle and pumped through a hose for bagging as shown in Fig. 5.

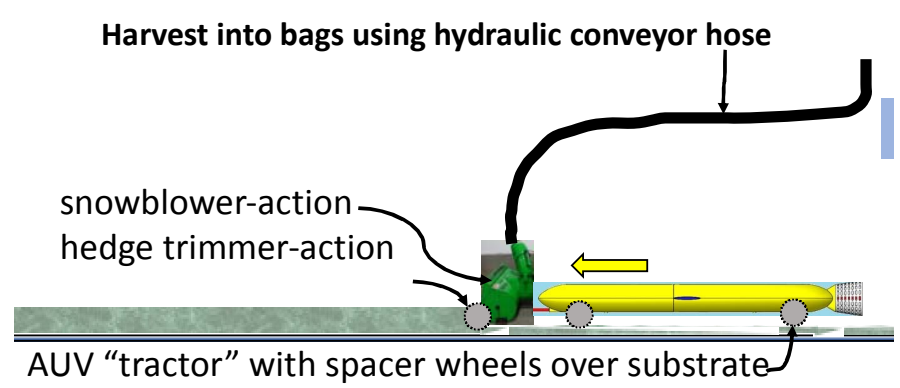

Fig. 5. Harvesting Gracilaria tikvahiae using an automated cutter and bagging system. 
Relatively small (20- to 40-cm diameter) wheels on the slightly negatively-buoyant automated underwater vehicle (AUV) maintain a specified distance above the net. A hose connected to a pump conveys cut macroalgae to the bagging system. A similar system could be used for kelp, except that the AUV would be free floating (without wheels) to cut at the optimal height to facilitate rapid regrowth, and the kelp would rise to the surface to be collected by a treadmill as shown in Fig. 6.

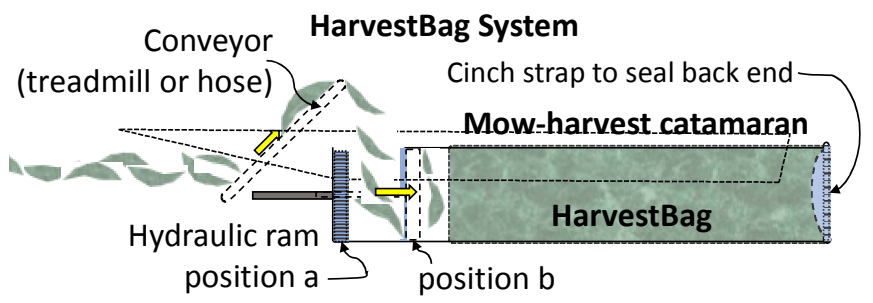

Fig. 6. Collecting treadmill and hydraulic bagging system

Algae will be compressed using a hydraulic ram into either a porous or impermeable bag with a porous end to allow water to escape (Fig. 6). Once full, both ends will be sealed and the bag will be picked up by a remotely piloted tug for energy processing. Fig. 7 shows the towing system conceived by C.A. Goudey and Associates. ${ }^{4}$

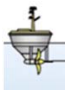

Fig. 7. Side view of a towing system for transporting seaweed.

Concept papers submitted to ARPA-E OPEN 2018 explain the benefits of harvesting macroalgae into impermeable geosynthetic membrane containers for either direct energy processing [12] or storage to even out the flow of product to the energy processor [13].

\section{E. Wave Energy Power System}

Texas A\&M is developing a wave-energy device described in their ARPA-E OPEN 2018 concept paper [14], which is competitive with solar PV for powering offshore aquafarms. Wave-tank tests suggest that the Surface Riding Wave Energy Converter could eventually have a levelized cost of electricity below $\$ 0.35 / \mathrm{kWh}$.

\section{F. Wide Applicability}

Fig. 8 shows over 5 million available hectares (in green) between 50- and 100-m depths in the GoM. The unshaded areas have other uses including military, shipping, oil and gas, etc.

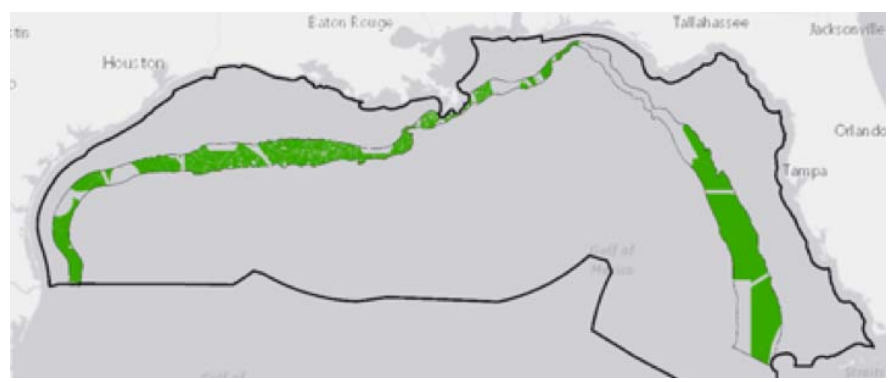

Fig. 8. GoM area between 50 and $100 \mathrm{~m}$ deep available for Ocean Forests (prepared by NOAA).

\section{G. Technoeconomic Analysis}

Current projections show high variability in \$/DMT with significant uncertainties due to:

- Yield in DMT/ha/yr ranging from 30 (normal) to 120 (if Lapointe's 1978 results are achieved),

- Density at time of mowing ranging from 1 to $10 \mathrm{DMT} / \mathrm{ha}$,

- Sufficient growth rate, which is dependent on nutrient availability, which is, in turn, affected by the percentage of incoming organic nutrients that are transformed by the shellfish and other animals into inorganics that stay in the ocean forest long enough to be absorbed by the macroalgae, and

- $\quad$ Rising ocean temperatures, which could decrease yields.

If these uncertainties can be resolved favorably, it is possible that Ocean Forests could grow and harvest even a small macroalgae, such as Gracilaria tikvahiae, for $<\$ 80 / \mathrm{DMT}$, while simultaneously producing large quantities of food for humans and animals.

\section{H. Future Research}

MARINER has nine teams competing for three at-sea demonstrations. Fig. 9 shows a possible location for a onehectare Phase 2 demonstration to prove the concepts required for breakthrough yields. A menu for Phase2 projects includes:

A four-sided structure with substrate appropriate for:

- Automated planting of any tropical macroalgae,

- Testing other seeding and harvesting arrangements,

- Frequent mowing to measure growth rates and potential yields,

- Adding depth control to prove this component,

- Shellfish to quantify nutrient conversions,

- Demonstration of the mow-harvest into bags, perhaps with a modified AlgeaNova system ${ }^{5}$. 


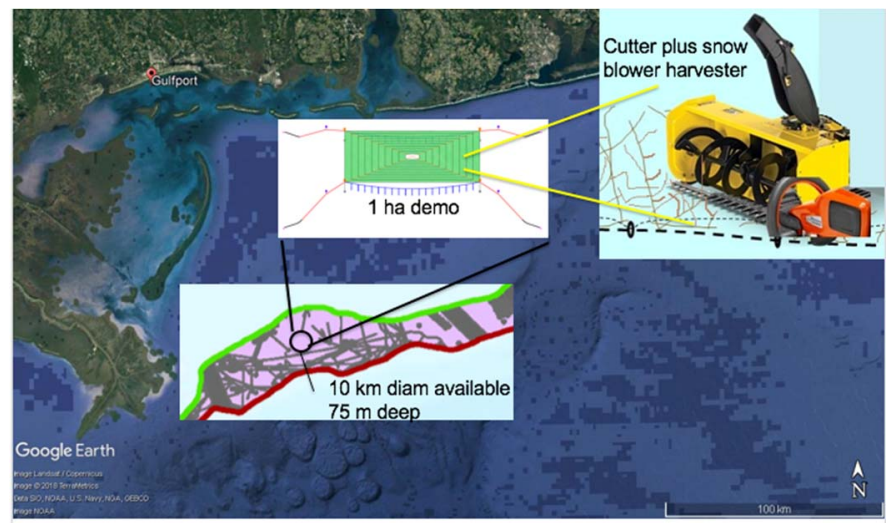

Fig. 9. Fig. 9. Potential location for a Phase 2 demonstration at $75 \mathrm{~m}$ depth

\section{DISCUSSION}

The team has a one-year contract with ARPA-E and will present its final report in April 2019. This paper presents a glimpse of the work in progress to be presented at the Oceans 18 Conference. Subsequent published papers will elaborate on the solutions outlined above.

\section{CONCLUSIONS}

Preliminary results show the possibility of significantly higher yields/area for any macroalgae and imply potentially profitable steps to meeting U.S. energy demand as follows:

(1) Make a small impact on global food security with products from permanent Ocean Forests, including shellfish and finfish or human food and macroalgae converted to livestock and fish feed. This can happen without nutrient recycling.

(2) Make a significant impact in global food security and human health by teaming with coastal water resource-recovery facilities to use treated wastewater to grow food. This closes the nutrient cycle of human food to plant food to human food.

(3) After many forests are operating successfully, energy companies recognize robust macroalgae feedstock supply. This starts a virtuous spiral expanding macroalgae-to-energy infrastructure, which extends the recycled nutrient supply to grow more macroalgae. The expanding spiral leads toward macroalgae biofuels meeting much of the global energy demand.

This system could eventually produce billions of gallons of biofuels without the use of any land, fresh water or added fertilizers (only the recycled nutrients from energy conversion).

\section{REFERENCES}

[1] B. E. Lapointe, Some aspects of the growth and yield of Gracilaria tikvahiae in culture, Aquaculture, 15, 185-193, 1978.

[2] ARPA-E Funding Opportunity No. DE-FOA-0001726, pp. 4-5 and 20, 2017. (Downloaded from https://arpa-e-foa.energy.gov)

[3] B. H. Buck, N. Nevejan, M. Wille, M. D. Chambers, and T. Chopin, Chapter 2. Offshore and multi-use aquaculture with extractive species: seaweeds and bivalves, 48-51. In B.H. Buck and R. Langan (eds.), Aquaculture Perspective of Multi-Use Sites in the Open Ocean, DOI: 10.1007/978-3-319-51159-7_2, 2017.

[4] M.D. Chambers et al., unpublished.

[5] University of New Hampshire Open Ocean Aquaculture research farm: http://ooa.unh.edu.
[6] N. Goseberg, M. D. Chambers, K. Heasman, D. Fredriksson, A. Fredheim, and T. Schlurmann, Technological approaches to longline- and cagebased aquaculture in open ocean environments, Chapter 3 in B. H. Buck and R. Langan (eds.), Aquaculture Perspective of Multi-Use Sites in the Open Ocean, DOI 10.1007/978-3-319-51159-7_3, 2017.

[7] C.F.D. Gurgel and S. Fredericq, Phylogeography of Gracilaria tikvahiae (Gracilariaceae, Rhodophyta): A study of genetic discontinuity in a continuously distributed series based on molecular evidence, Journal of Phycology, 40, 748-758, DOI: 10.1111/j.1529-8817.2004.03070.x, 2004.

[8] FAO Training Manual on Gracilaria Culture and Seaweed Processing in China. Zhanjiang Fisheries College, People's Republic of China, 1990.

[9] T. R. Keen and S. M. Glenn, Shallow water currents during Hurricane Andrew, Journal of Geophysical Research Atmospheres, 104, C10, 23,443-23,458, 1999.

[10] M. I. Lucas, R. C., Newell, and B. Velimirov, Heterotrophic utilisation of mucilage released during fragmentation of kelp (Ecklonia maxima and Laminana pallida) II. Differential utilisation of dissolved organic components from kelp mucilage. Marine Ecology Progress Series 4(1):43-55, 1981. DOI: 10.3354/meps004043

[11] M. Zaraska, Shrinking animals. Scientific American, 49, 2018.

[12] K. Hopkins, In-Ocean Submersible Bag Biomass Biorefinery, 2018. Unpublished but posted at https://drive.google.com/open?id=1Fus7icjapwqu_3yeY31JB4Sig7ehgQnQ.

[13] S. F. DiMarco, Submersible Bag Biomass Storage with Dewatering, 2018. Unpublished but posted at https://drive.google.com/file/d/1En2p35Th6dsC-6yx-oJ34cen9kMoPAO/view.

[14] H. Y. Kang, M. H. Kim, K. A. Chang, and H. A. Toliyat, Surface riding wave energy converter, 2018. Unpublished but posted at: https://drive.google.com/open?id=1f1_SfQc_6SCkuuoqwKat98rfRzGU PUjN. 